\title{
A Current Sensor Based on the Giant Magnetoresistance Effect: Design and Potential Smart Grid Applications
}

\author{
Yong Ouyang ${ }^{1}$, Jinliang He ${ }^{1, *}$, Jun $\mathrm{Hu}^{1}$ and Shan X. Wang ${ }^{1,2}$
}

1 State Key Lab of Power Systems, Department of Electrical Engineering, Tsinghua University, Beijing 100084, China; E-Mails: ouyy07@gmail.com (Y.O.Y.); hjun@tsinghua.edu.cn (J.H.)

2 Center for Magnetic Nanotechnology, Stanford University, 450 Serra Mall, Stanford, CA 94305, USA; E-Mail: sxwang@stanford.edu

* Author to whom correspondence should be addressed; E-Mail: hej1@tsinghua.edu.cn; Tel.: +86-10-6278-8811; Fax: +86-10-6278-4709.

Received: 27 September 2012; in revised form: 29 October 2012 / Accepted: 30 October 2012 / Published: 9 November 2012

\begin{abstract}
Advanced sensing and measurement techniques are key technologies to realize a smart grid. The giant magnetoresistance (GMR) effect has revolutionized the fields of data storage and magnetic measurement. In this work, a design of a GMR current sensor based on a commercial analog GMR chip for applications in a smart grid is presented and discussed. Static, dynamic and thermal properties of the sensor were characterized. The characterizations showed that in the operation range from 0 to $\pm 5 \mathrm{~A}$, the sensor had a sensitivity of $28 \mathrm{mV} \cdot \mathrm{A}^{-1}$, linearity of $99.97 \%$, maximum deviation of $2.717 \%$, frequency response of $-1.5 \mathrm{~dB}$ at $10 \mathrm{kHz}$ current measurement, and maximum change of the amplitude response of $0.0335 \% \cdot{ }^{\circ} \mathrm{C}^{-1}$ with thermal compensation. In the distributed real-time measurement and monitoring of a smart grid system, the GMR current sensor shows excellent performance and is cost effective, making it suitable for applications such as steady-state and transient-state monitoring. With the advantages of having a high sensitivity, high linearity, small volume, low cost, and simple structure, the GMR current sensor is promising for the measurement and monitoring of smart grids.
\end{abstract}

Keywords: current sensing; giant magnetoresistance; sensor design; smart grid 


\section{Introduction}

Smart grids are the latest trend in the World's power system. They represent an evolution towards a more optimized and sustainable energy system using the implementation of information technology [1-3]. Advanced sensing and measurement techniques are key technologies in a smart grid to successfully provide accurate information for real-time monitoring and control of the entire distributed power system.

The giant magnetoresistance (GMR) effect was discovered in some ferromagnetic metallic materials. The resistance of these materials decreases greatly under the influence of external magnetic field. Grünberg and Fert separately discovered this phenomenon in 1988 [4-6], which revolutionized the field of data storage and magnetic measurement. For their significant contributions, they were awarded the 2007 Nobel Prize for Physics [7]. Since IBM Corporation developed the first commercial read head based on the GMR effect in 1997, the area density of the devices has grown hundreds of times $[8,9]$.

In the field of magnetic measurement, GMR sensors are widely utilized for position and angular sensing, current sensing and biological sensing. A number of integrated detectors containing GMR elements with wide bandwidth have been developed for motor drives, power electronic modules, and regulator modules [9-13]. A GMR sensor for highly-sensitive stress measurement has been introduced [14]; additionally, an eddy current testing probe based on the spin-valve GMR effect has been developed for inspecting printed circuit boards [15]. In the field of biological sensing, GMR sensors have been applied in crop production for sensing growth conditions, fertilization, and irrigation; GMR sensors are also useful for plant protection, harvesting, and fleet controls [16]. Sensors based on the GMR effect have also been used in protein and DNA assays, to perform molecular diagnostics of diseases [17-20].

In order to realize linear sensing, the sensed field range, linearity, and sensitivity are three important parameters. For example, the sensitivity is $25 \mathrm{mV} \cdot \mathrm{A}^{-1}$, and the sensed field range is from 0 to $\pm 10 \mathrm{~mA}$ in certain linear spin-valve GMR sensors reported in the literature [21-24].

In this work, we designed the structure of a GMR sensor for current sensing that can be implemented in a smart grid. In addition, the characteristics of the GMR sensor, such as its static characteristics, dynamic characteristics and thermal characteristics were tested.

\section{Principle of Operation}

Current flowing through a metal wire creates a magnetic field around the wire. The relationship between the current and magnetic field is described by the Biot-Savart Law. The principle of operation of the GMR current sensor is shown in Figure 1. The current flowing through the metal wire can be measured from the output of the GMR current sensor, when the GMR current sensor is placed close to the wire. The output of the GMR current sensor can be generally described by:

$$
V=F_{G M R}\left(I, f, T, V_{S}, \mu, r, \theta, B_{D}\right)
$$

where $V$ is the output voltage of the GMR current sensor, $I$ and $f$ are the magnitude and frequency of the current passing through the wire, respectively, $T$ is the environmental temperature, $V_{S}$ is the power supply voltage of the sensor, $\mu$ is the relative permeability around the sensor, $r$ is the distance from the 
wire to the sensor, $\theta$ is the angle between the magnetic field direction and the axis of sensitivity of the GMR chip, and $B_{D}$ is the surrounding parasitic magnetic field.

Figure 1. Principle of operation of the GMR current sensor. $I$ is the current passing through the wire, and the direction is from left to right. $B$ is the magnetic field generated by the current $I$, and the direction is rotating around the wire. $r$ is the distance from the wire to the sensor, and $\theta$ is the angle between the magnetic field direction and the axis of sensitivity of the GMR chip.

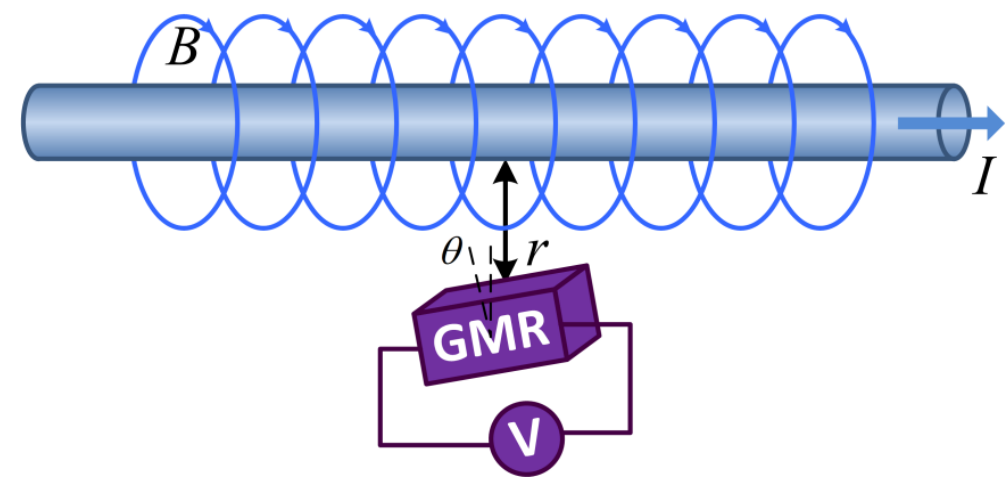

\section{Sensor Design}

The sensor system contains three main subsystems: the sensing head, the signal processing subsystem and the power supply subsystem. Each subsystem affects the overall performance of the sensor. The block diagram of the sensor system is shown in Figure 2.

Figure 2. Block diagram of sensor system. The whole sensor system contains three main subsystems: The function of the sensing head is to convert the current signal measured to the voltage signal. The function of the signal processing subsystem is to process the voltage signal from the sensing head and calculate the current measured. The function of the power supply subsystem is to provide the power source for the whole sensor system.

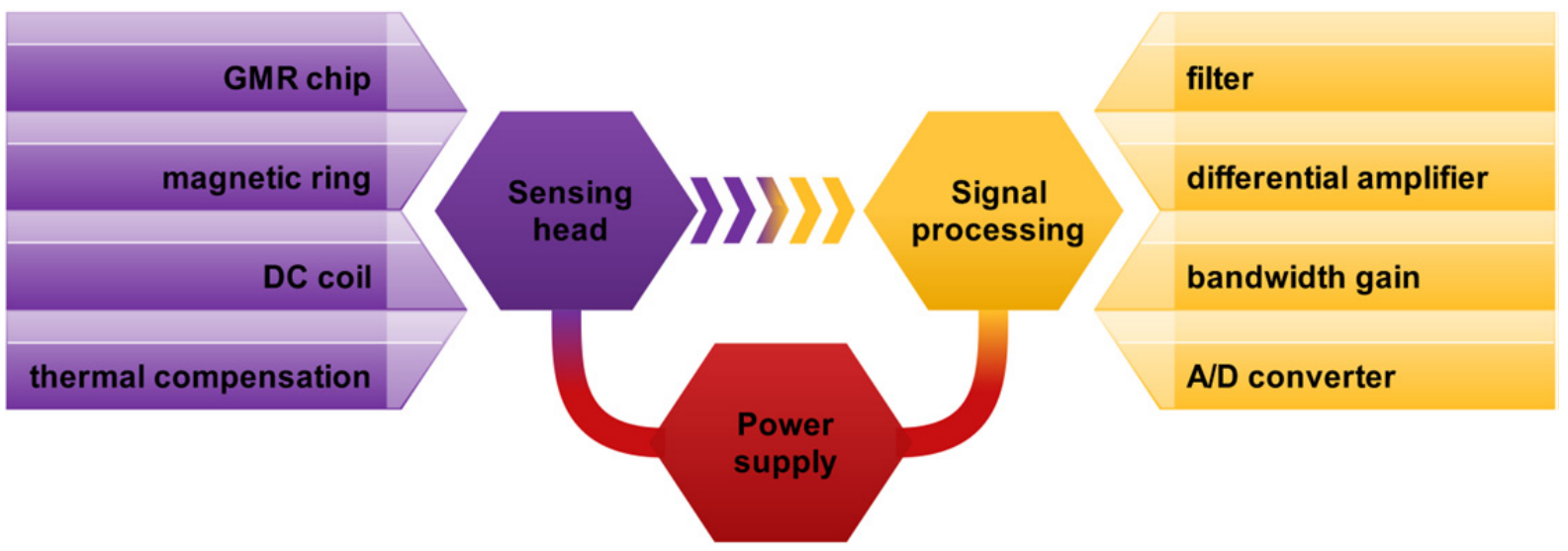

\subsection{Sensing Head}

The sensing head, which is shown in Figure 3, is the kernel of the whole measuring system, and its function is to convert the current signal measured into the voltage signal that can be measured easily. 
A wire with the current line to be measured passes through a magnetic ring. A DC coil is uniformly wrapped around the magnetic ring. A GMR chip is placed in the gap of the magnetic ring, and a thermal compensation unit is used to compensate the temperature drift of the GMR chip. The output of the GMR chip is subsequently processed by the signal processing subsystem.

Figure 3. Schematic diagram of sensing head.

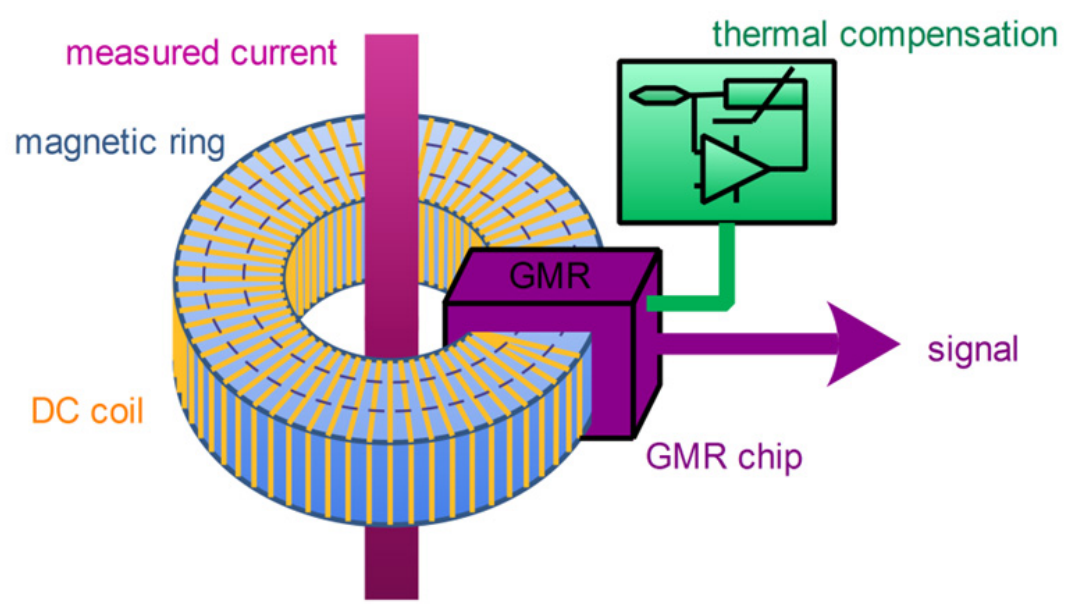

In order to convert the magnetic signal to a voltage signal that can be easily measured, a Wheatstone bridge is used in the design of the GMR chip (Figure 4). In the GMR chip, four resistive elements are arranged as follows: two are active sensing elements and two are shielded elements. Due to limitations in material processing and manufacturing technology, the four resistive elements cannot be manufactured identically, so their magnitudes are slightly different when the magnetic field is not present.

Figure 4. Wheatstone bridge of GMR chip. The two shield resistors are shielded elements, and the two GMR resistors are active elements. $\mathrm{V}+$ and $\mathrm{V}-$ are two terminals of the power supply of the GMR chip. OUT + and OUT- are the positive and negative output of the GMR chip.

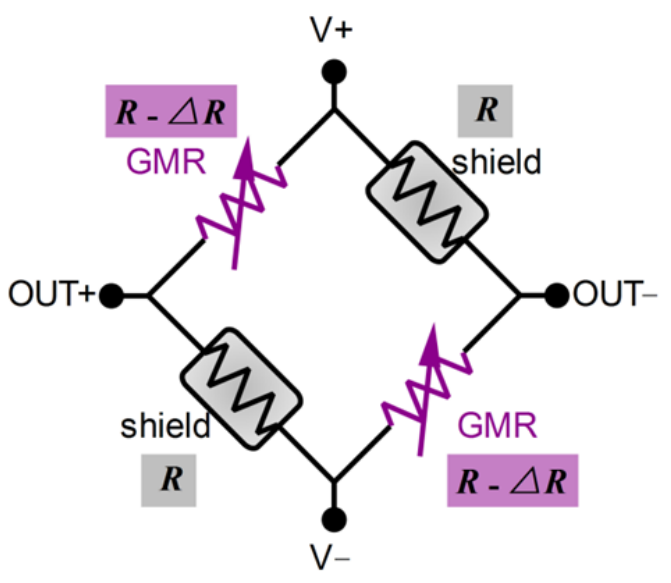


The output of the GMR chip is differential, and can be described as follows:

$$
\begin{aligned}
\text { Vout }_{+} & =\frac{R}{2 R-\Delta R}\left(\mathrm{~V}_{+}-\mathrm{V}_{-}\right)+\mathrm{V}_{-} \\
\text {Vout }_{-} & =\frac{R-\Delta R}{2 R-\Delta R}\left(\mathrm{~V}_{+}-\mathrm{V}_{-}\right)+\mathrm{V}_{-} \\
\text {Vout }_{+}-\text {Vout }_{-} & =\frac{\Delta R}{2 R-\Delta R}\left(\mathrm{~V}_{+}-\mathrm{V}_{-}\right) \approx \frac{\Delta R}{2 R}\left(\mathrm{~V}_{+}-\mathrm{V}_{-}\right)
\end{aligned}
$$

where Vout $_{+}$and Vout - are the voltage outputs of the GMR chip, $V_{+}$and $V_{-}$are the power supply voltages of the GMR chip, and $R$ is the intrinsic resistance of the four elements when no magnetic field is applied. $\Delta R$ is the change of the resistance of the two active elements under a magnetic field, and $\Delta R$ is linearly proportional to the magnetic field to be measured.

The MR ratio $(\Delta R / R)$ is about $7 \%$. Because $\Delta R$ is much smaller than $R$, the output of the GMR chip can be treated as linearly proportional to $\Delta R$.

The magnetic ring is made of a soft ferromagnetic material with a large relative permeability, and its structure is shown in Figure 5. It can make the magnetic field to remain stable and nearly unaffected by position fluctuation of the current line. The magnetic field in the gap of the magnetic ring can be described as:

$$
B=\frac{\mu_{0} I}{d+\frac{2 \pi r-d}{\mu_{r}}} \approx \frac{\mu_{0} I}{d}
$$

where $B$ is the flux density, $\mu_{0}$ is the permeability of vacuum, $\mu_{r}$ is the relative permeability of the magnetic ring, $r$ is the average radius of the magnetic ring, $d$ is the length of the gap, and $I$ is the measured current.

Figure 5. The structure of the magnetic ring. The magnetic ring is made of silicon steel. The size of the magnetic ring is as follows: the average radius $r$ is $5 \mathrm{~cm}$, the width $l$ is $1 \mathrm{~cm}$, the thickness $h$ is $2 \mathrm{~cm}$, and the gap $d$ is $1 \mathrm{~cm}$.

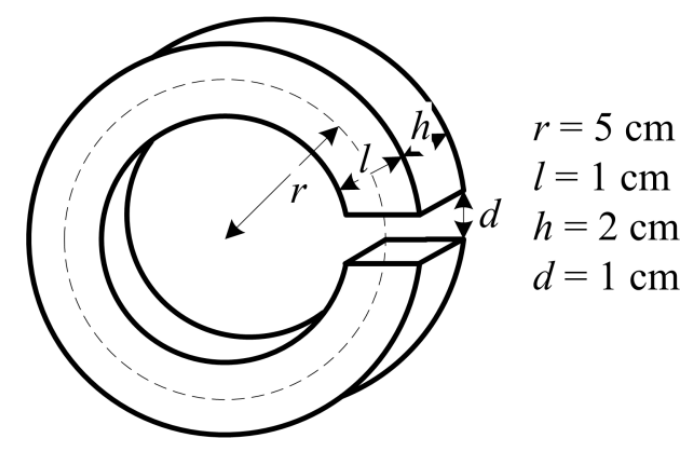

Because $\mu_{r}$ of ferromagnetic materials is usually in the range of 1,000 to 10,000 , then $(2 \pi r-d) / \mu_{r} \approx 0$. Therefore, $B$ approximately only depends on $d$ and $I$. Moreover, the magnetic ring can greatly amplify the magnetic field to be measured, enabling the GMR current sensor to measure a smaller current. The magnetic ring can also shield unwanted signals, such as neighboring current lines and the geomagnetic field. 
The number of DC coil turns wound around the magnetic ring is 500, and the current of DC coil is $10 \mathrm{~mA}$. Therefore, the DC magnetic field in the gap is about 6.28 Oe.

The GMR chip used in the experiment is a product of the NVE Corporation (Part Number: AA002-02); and its multilayered structure is based on a Ni-Fe-Co magnetic layer and $\mathrm{Cu}$ spacer. The typical transfer curve of the multilayered GMR chip is inverse-V-shaped. As it cannot identify the direction of the magnetic field to be measured; the DC coil superposes the magnetic field created by the passing current; so the GMR chip works on unipolar field; which can reduce hysteresis and realize bipolar measurement. Under a constant voltage supply, the GMR sensor signal output will fall as temperature rises. Because the GMR sensor signal is related to the power supply, a positive temperature control voltage supply is added to feed the GMR current sensor, as shown in Figure 3, to compensate for the temperature drift.

\subsection{Signal Processing}

The signal processing subsystem is used to process the voltage signal from the sensing head and calculate the current measured, and its schematic is shown in Figure 6.

Figure 6. Schematic diagram of signal processing subsystem.

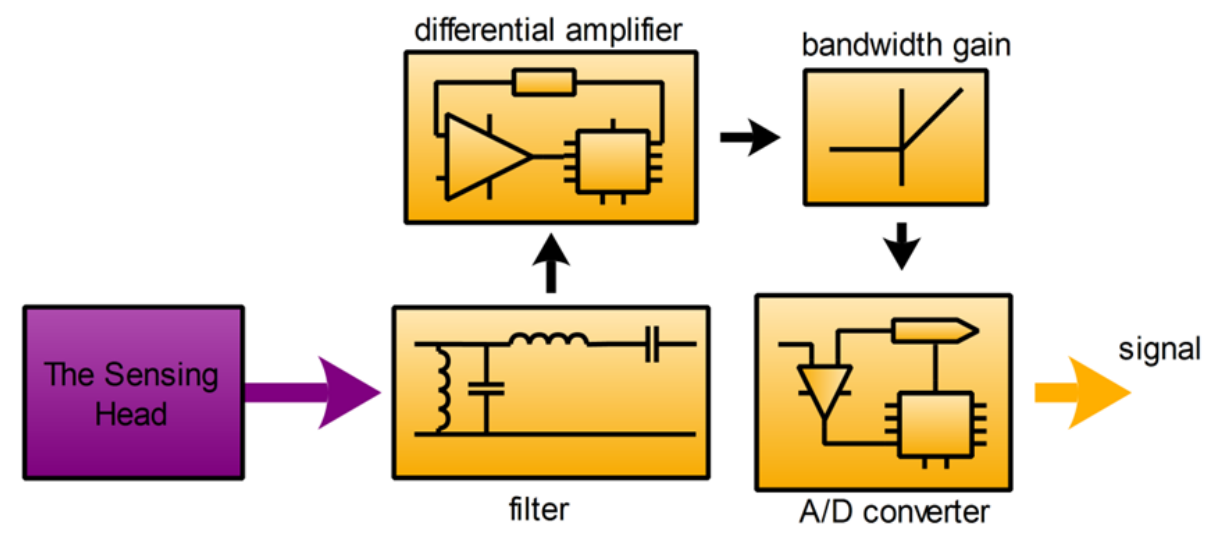

As shown in the Figure 6, the filter is a low-pass filter used to remove some interfering signals, especially high frequency noise of the voltage signal from the sensing head. The output of the GMR chip includes common-mode signal, and it is about half of the power supply. The differential amplifier is used to remove useless common-mode noise, and to amplify useful differential signal, and the model used in the experiment is an instrumentation amplifier produced by Texas Instruments (Part Number: INA114). The bandwidth gain unit is used to improve the frequency response of the GMR current sensor. Finally, the A/D converter is used to convert the analog signal from the GMR chip to digital signal, and the model used in the experiment is an USB digitizer produced by National Instruments (Part Number: USB-5133).

\subsection{Power Supply}

The power supply subsystem is used to provide a stable power source for the whole system, such as the voltage source of the GMR chip, the adjustable current source of the DC coil, and reference voltages of the system. A MH-Ni rechargeable battery pack is applied to the power source of the 
system. Because the voltage of battery pack fluctuates from $13 \mathrm{~V}$ to $17 \mathrm{~V}$, voltage regulators are used to provide stable voltages for the whole system.

\subsection{Circuit Design}

The circuit diagram of the sensor system is shown in Figure 7. It contains three parts: the power supply subsystem, the sensing head and the differential amplifier unit. The power supply subsystem provides following power sources: $\pm 10 \mathrm{~V}$ power source for the operational amplifier and the differential amplifier, $\pm 5 \mathrm{~V}$ power source for the GMR chip, $1 \mathrm{~mA} \sim 100 \mathrm{~mA}$ DC current source for the DC coil and $5 \mathrm{~V}$ reference voltage for the system.

Figure 7. Circuit diagram of the sensor system. The circuit diagram contains the power supply subsystem $(\mathbf{a}, \mathbf{b}, \mathbf{c})$, the sensing head subsystem $(\mathbf{d}, \mathbf{e})$ and the differential amplifier unit (f). VTCout+ and VTCout- are outputs of the thermal compensation unit, connected to power supply to the GMR chip. Output is the output of the differential amplifier, and is connected to the USB digitizer (USB-5133). GMROut+ and GMROut-, two red measuring probes shown in the figure, are outputs of the GMR chip. In order to get the typical performance of the GMR current sensor and eliminate the influence of the thermal compensation unit and the differential amplifier unit, the power supply of the GMR chip is $\pm 5 \mathrm{~V}$, and the direct measuring terminals (GMROut+ and GMROut-) are the outputs of the GMR chip in the experiment.

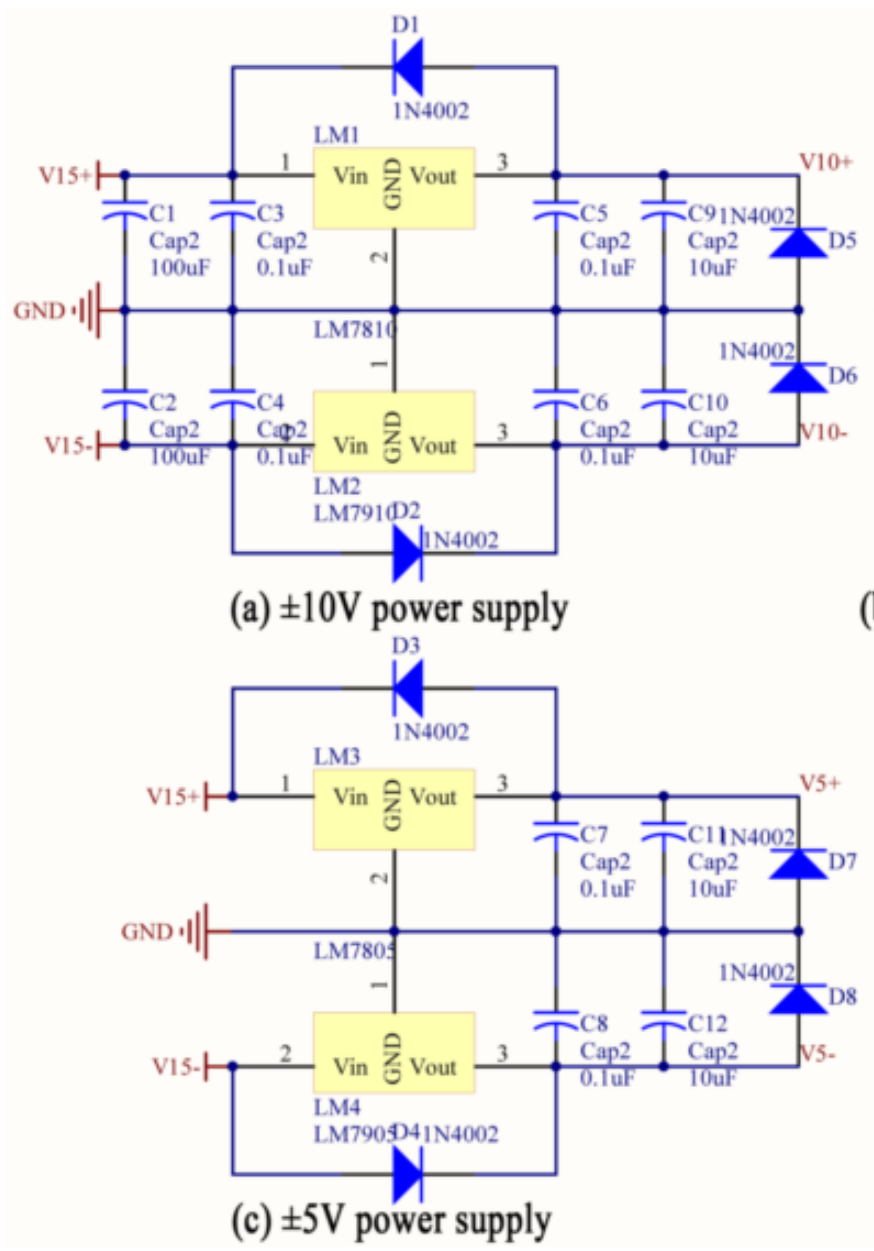

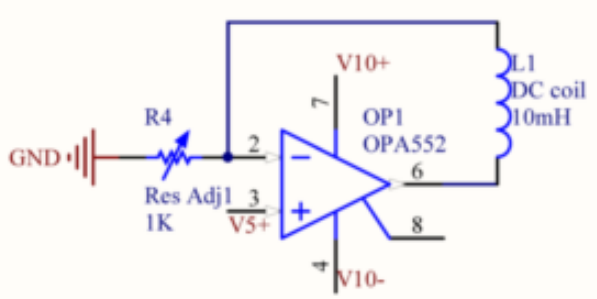

(b) $1 \mathrm{~mA} \sim 100 \mathrm{~mA}$ DC current source

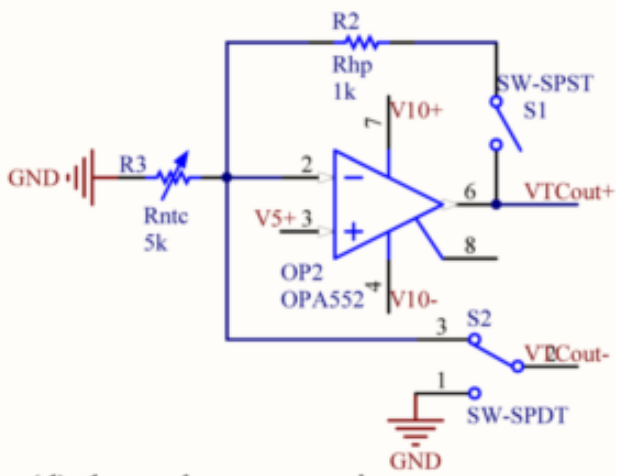

(d) thermal compensation 
Figure 7. Cont.

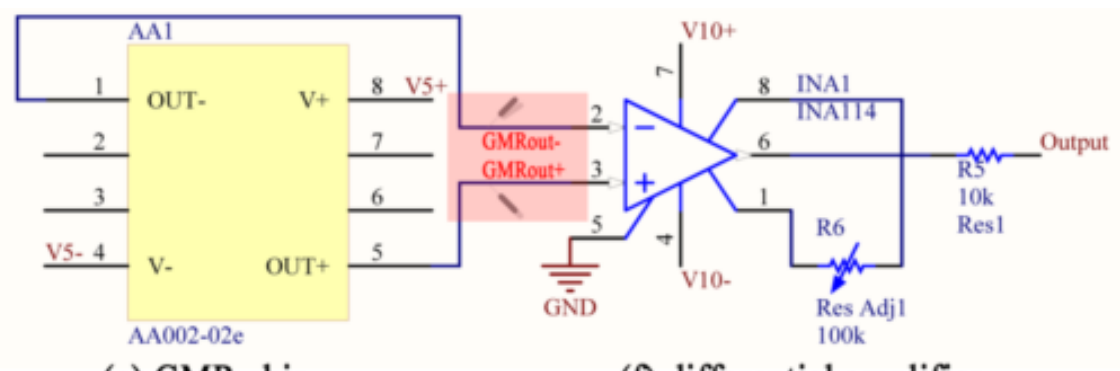

(e) GMR chip

(f) differential amplifier

In order to get the typical performance of the GMR current sensor before being processed by the thermal compensation unit and the differential amplifier unit, the terminals of the power supply of the GMR chip was connected to the $\pm 5 \mathrm{~V}$ outputs of the power supply subsystem, and the voltages were directly measured from the two outputs of the GMR chip, as shown in Figure 7.

\section{Typical Performance}

The performance of the GMR current sensor, which consists of static, dynamic and thermal characteristics, determines its application. Some performance parameters of the sensors were experimentally characterized and are presented below.

\subsection{Static Characteristics}

The static characteristics include the sensor's range, sensitivity, linearity and accuracy. The GMR current sensor has high sensitivity, as much as ten times the sensitivity of a Hall effect-based sensor [25]. As the GMR chip is supplied by a dual power supply $( \pm 5 \mathrm{~V})$, the output voltage offset is less than $5 \mathrm{mV}$ when the measured current and the bias current of DC coil are both $0 \mathrm{~A}$, and the value is $149 \mathrm{mV}$ when the measured current and the bias current of DC coil are respective $0 \mathrm{~A}$ and $10 \mathrm{~mA}$. The effect of the DC coil was eliminated and ignored in the following performance analyses. When the current to be measured was 10 A peak to peak with frequency at $50 \mathrm{~Hz}$, the environmental temperature $T$ was $20^{\circ} \mathrm{C}$, the power supply voltage of the sensor $V_{S}$ was $\pm 5 \mathrm{~V}$, the distance from the wire to the sensor $r$ was $5 \mathrm{~cm}$, the length of the magnetic ring's gap $d$ was $1 \mathrm{~cm}$, and the angle between the magnetic field direction and the axis of sensitivity $\theta$ was $0^{\circ}$, the output waveforms of the GMR current sensor is shown in Figure 8. The linear response of the sensor is shown in Figure 9.

In the case of $0 \sim \pm 5 \mathrm{~A}$ DC input range, the sensitivity of the GMR current sensor was $27.9963 \mathrm{mV} \cdot \mathrm{A}^{-1}$, and the zero-current drift was $3.8634 \mathrm{mV}$, and the linearity was 0.99951 . In the case of $0 \sim \pm 5 \mathrm{~A}$ AC input range, the sensitivity of the GMR current sensor was $28.0064 \mathrm{mV} \cdot \mathrm{A}^{-1}$, and the zero-current drift was $2.5319 \mathrm{mV}$. The linearity was 0.99972 , which became higher as the measured current range decreased. Figure 9 also shows that the largest errors occurred when the measured currents were near $-5 \mathrm{~A}$. The measurement resolution of the GMR current sensor is $10 \mathrm{~mA}$ for the $0 \sim \pm 5$ A input range. 
Figure 8. Waveforms of GMR current sensor. Current is the AC current passing through the wire, measured by the Tektronix TCP312. GMROut+ and GMROut- are outputs of the GMR chip. GMROut is the differential output of the GMR chip.

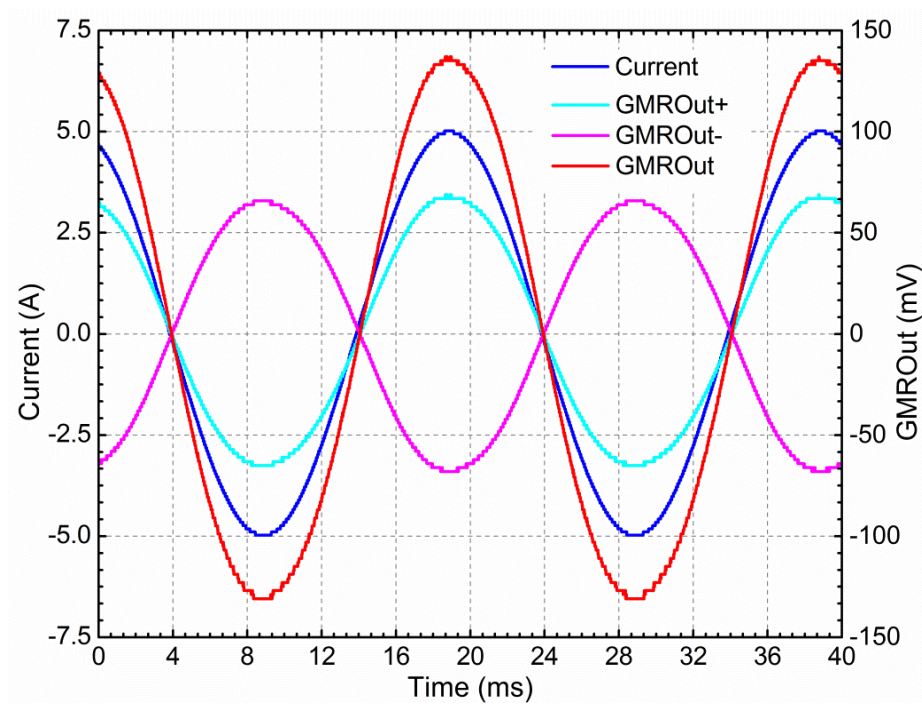

Figure 9. (a) DC linear analysis of GMR current sensor. (b) AC linear analysis of GMR current sensor. The output voltage offset is less than $5 \mathrm{mV}$ when the measured current and the bias current of DC coil are both 0 , and the value is $149 \mathrm{mV}$ when the measured current and the bias current of DC coil are respective $0 \mathrm{~A}$ and $10 \mathrm{~mA}$. GMROut is the differential output of the sensor in the corresponding measured current, and the effect of bias current of DC coil has been eliminated. Linearfit is the data of linear regression.

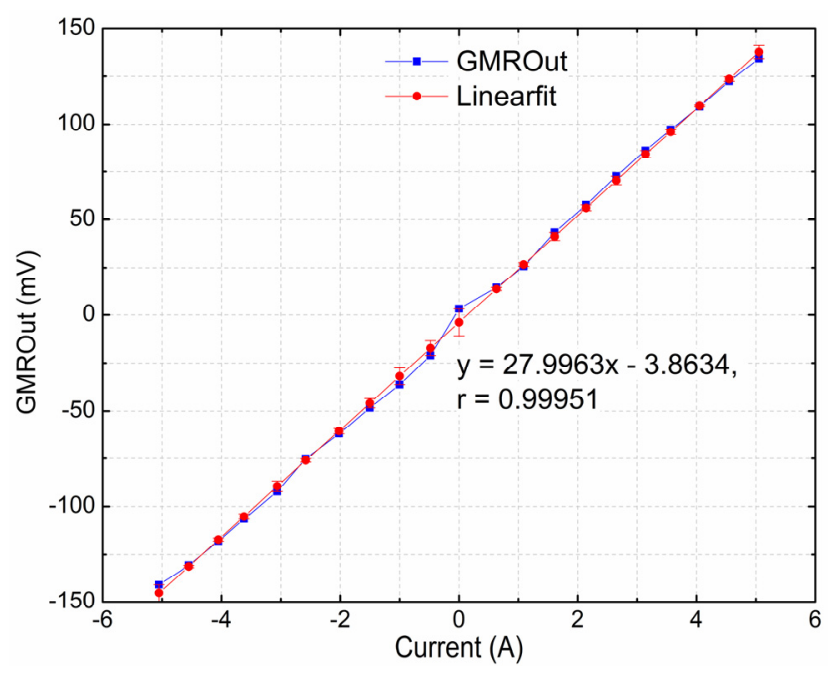

(a)

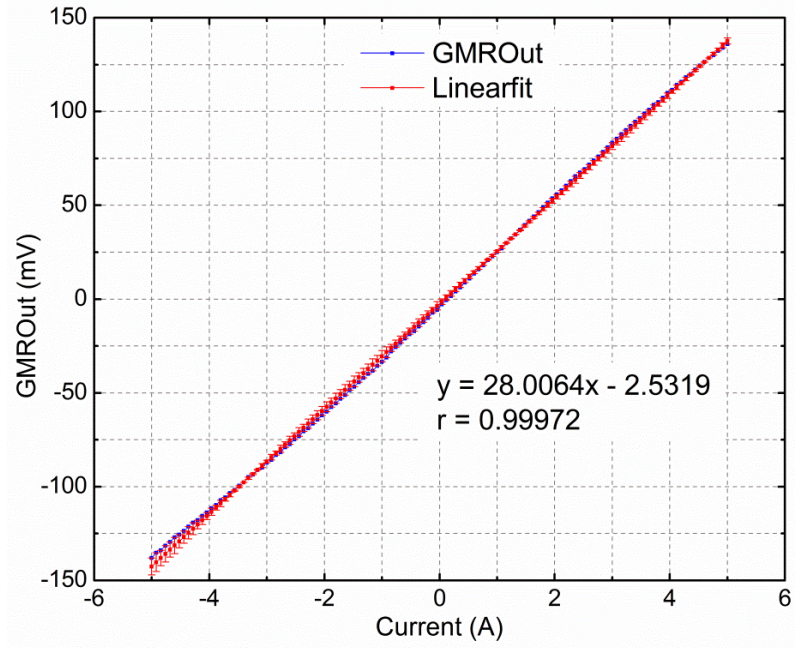

(b)

Accuracy is one of the most important parameters when designing sensors. As shown in Figure 10, when the input $\mathrm{AC}$ current was below $10 \mathrm{~A}$ peak to peak, the input current can be obtained from the output of the GMR current sensor, using the following fitting equation:

$$
I=0.03626 U+0.03007
$$


where $I$ is the measured input current in Ampere, $U$ is the output of the GMR current sensor in millivolts. The maximum deviation of Equation (4) is $2.717 \%$.

Figure 10. Accuracy analysis of GMR current sensor. True value is the true value of the current measured. Measured value is the calculated value of the Equation (4), according to measured value of the sensor. Errors is the deviation of the system from the true value. When the measured current range is $0 \sim \pm 5 \mathrm{~A}$, The function of the current is $I=0.036255 \mathrm{U}$ +0.030072 , and the maximum deviation is $2.717 \%$ at $-5 \mathrm{~A}$.

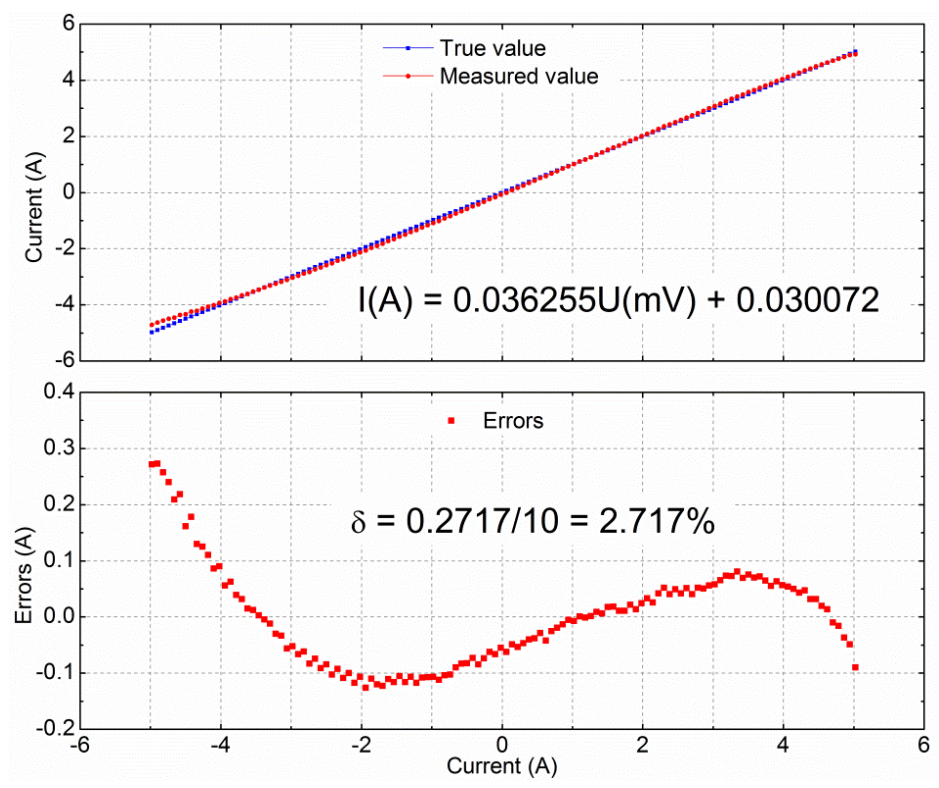

The related coefficients can be adjusted to appropriate values using the differential amplifier unit. Usually, the lower the measured current range, the higher the accuracy and the lower errors. This empirical finding is shown in Table 1 . When the measured current range was $0 \sim \pm 2 \mathrm{~A}$, the linearity increased to $99.993 \%$, and the maximum deviation decreased to $1.757 \%$.

Table 1. Static characteristics of GMR current sensor in different measured range.

\begin{tabular}{|c|c|cc|}
\hline Range & Linearity & Maximum deviation & Equation \\
\hline $0 \sim \pm 5 \mathrm{~A}$ & $99.972 \%$ & $2.717 \%$ & $I=0.03626 U+0.03007$ \\
\hline $0 \sim \pm 2 \mathrm{~A}$ & $99.993 \%$ & $1.757 \%$ & $I=0.03626 U+0.00797$ \\
\hline
\end{tabular}

\subsection{Dynamic Characteristics}

The multilayered GMR chip can sense high frequency magnetic fields up to $1 \mathrm{MHz}$. By measuring pure sinusoidal current with different frequencies, the frequency response of the sensor was obtained, which is shown in Figure 11. The GMR current sensor worked very stably from $50 \mathrm{~Hz}$ to $1 \mathrm{kHz}$. The amplitude response was $28 \mathrm{mV} \cdot \mathrm{A}^{-1}$, and varied less than $5 \%$, about $-0.45 \mathrm{~dB}$ at the reference amplitude response of $50 \mathrm{~Hz}$. The phase response lagged by approximately $-6^{\circ}$ but only varied a little. From $1 \mathrm{kHz}$ to $10 \mathrm{kHz}$, the amplitude and phase response of the GMR current sensor were gradually attenuated. The amplitude response attenuation was about $-1.5 \mathrm{~dB}$ at the reference amplitude of $50 \mathrm{~Hz}$, and the phase response lagged from $-6^{\circ}$ to nearly $-33^{\circ}$. 
Figure 11. Frequency response of GMR current sensor. The way to obtain the frequency response is measuring pure sinusoidal current with different frequencies. At the reference frequency of $50 \mathrm{~Hz}$, the amplitude response is $0 \mathrm{~dB}\left(28 \mathrm{mV} \cdot \mathrm{A}^{-1}\right)$, and the phase response is $-6.13^{\circ}$ lag. The corresponding data is $-0.45 \mathrm{~dB}$ and $-7.62^{\circ}$ at $1 \mathrm{kHz},-1.5 \mathrm{~dB}$ and $-32.8^{\circ}$ at $10 \mathrm{kHz}$, respectively.

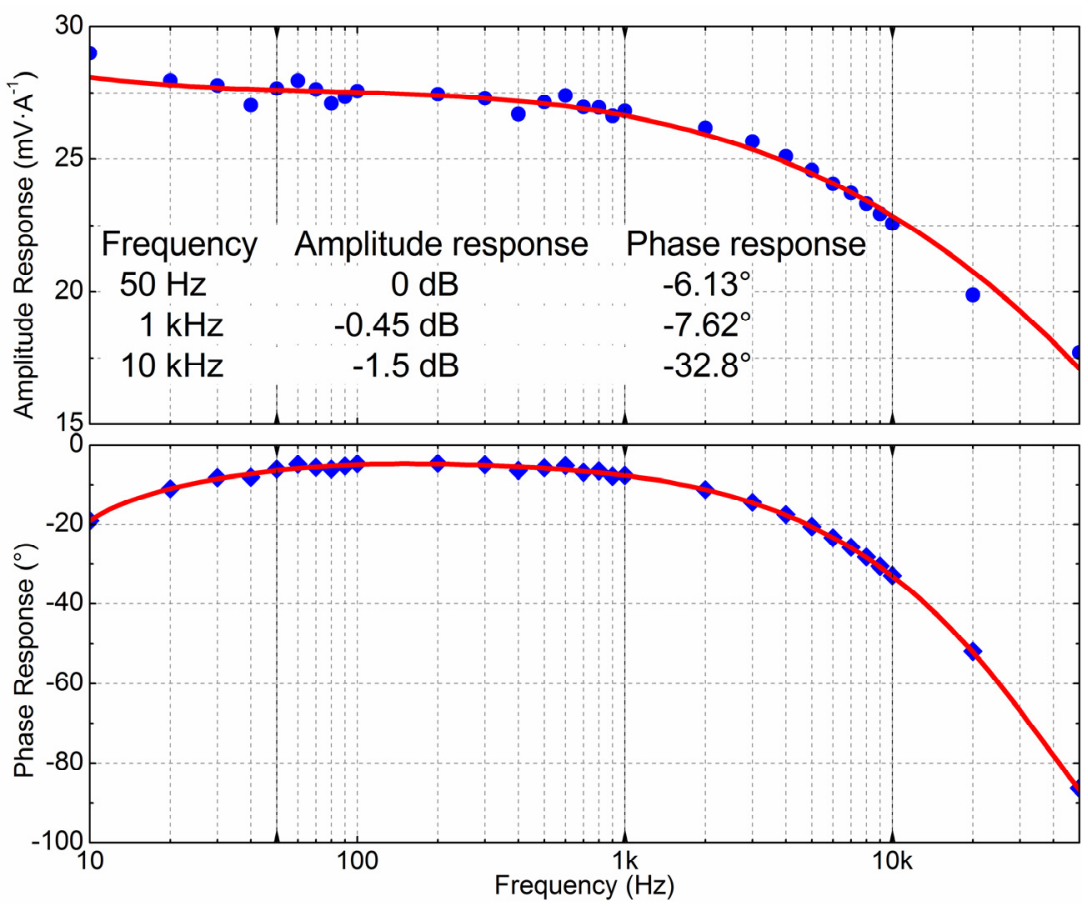

Figure 12. Step response of GMR current sensor. Current is the step current signal generated by the waveform generator Agilent 33250A, with the rising time of $6.58 \mu \mathrm{s}$. GMROut is the differential output of the GMR current sensor, with the rising time of $15.21 \mu \mathrm{s}$. Therefore, the rising time of the step response of the GMR current sensor is $8.63 \mu \mathrm{s}$, according to the Equation (5).

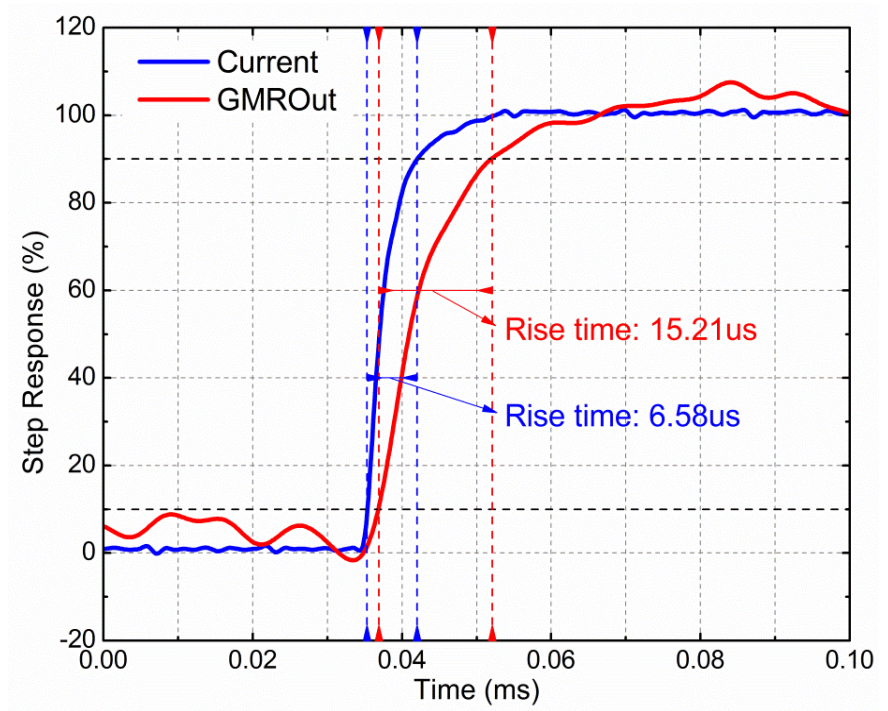

The step response of the GMR current sensor is shown in Figure 12. The step signal was generated by a waveform generator (Agilent 33250A). Measured using a Tektronix TCP312, the rise time of the 
step current was $6.58 \mu \mathrm{s}$, and the rise time of the output voltage of the GMR current sensor in response to the step current was $15.21 \mu \mathrm{s}$. It is recognized that an infinitely steep current step is impossible to be realized. Therefore, the rise time of the GMR current sensor is evaluated from the relation:

$$
T_{\text {rise }}=T_{\text {out }}-T_{\text {in }}
$$

where $T_{\text {rise }}$ is the rise time of the step response of the GMR current sensor, $T_{\text {out }}$ is the rise time measured on the output of the GMR current sensor, and $T_{\text {in }}$ is the rise time of the applied current step. Therefore, the rise time of the step response of the GMR current sensor was about $8.63 \mu$ s.

\subsection{Thermal Characteristics}

Thermal characteristic is another important performance parameter of a sensor. The working environment of the GMR current sensor can widely fluctuate, and the applications of the sensor are directly limited by the thermal characteristics of the sensor. To characterize the thermal property of the GMR sensor, we first define the maximum change of the amplitude response in temperature as:

$$
T M C A=\frac{\left(\frac{V_{O}}{I}\right)_{\max }-\left(\frac{V_{O}}{I}\right)_{\min }}{\left(\frac{V_{O}}{I}\right)_{T_{\mathrm{ref}}}} \times \frac{1}{\left(T_{\max }-T_{\min }\right)} \times 100 \%
$$

where $T M C A$ is the maximum change of the amplitude response in temperature, $V_{O} / I$ is the amplitude response of the GMR current sensor, $T$ is the working temperature, " $T_{\text {ref }}$ " indicates the value of the reference temperature, usually $20^{\circ} \mathrm{C}$, and "max" indicates the maximum value of amplitude response, and "min" indicates the minimum value of amplitude response.

The thermal response of the GMR current sensor with a constant voltage power supply and $50 \mathrm{~Hz}$ alternating input current is shown in Figure 13. Due to limitations in material processing and manufacturing technology, the four resistive elements shown in Figure 4 are slightly asymmetrical. Therefore, the magnitude of the positive output and the magnitude of the negative output of the sensor were slightly different. According to the feature of the Wheatstone bridge, there is a phase lag of $180^{\circ}$ between the positive output and negative output of the GMR current sensor, and the differential output has the same phase degree with the positive output of the GMR current sensor, as shown in Figure 13.

The differential output of the GMR current sensor decreased with rising temperature. The amplitude response was $28.43 \mathrm{mV} \cdot \mathrm{A}^{-1}$ at $-15{ }^{\circ} \mathrm{C}$, but decreased to $26.49 \mathrm{mV} \cdot \mathrm{A}^{-1}$ at $80{ }^{\circ} \mathrm{C}$. The $T M C A$ is $0.0751 \% \cdot{ }^{\circ} \mathrm{C}^{-1}$. In contrast, the phase response was independent of temperature, and the phase lag with respect to the input current was $-5.18^{\circ}$, as shown in Figure 13.

In order to sustain the high degree of accuracy of the GMR current sensor, thermal compensation measures, such as a constant current power supply, should be considered. A generalized impedance converter with reference input current can be utilized to perform the thermal compensation [26,27]. This compensation technique is compatible with the Wheatstone bridge circuit, and could successfully bring TMCA from $-0.024 \% \cdot{ }^{\circ} \mathrm{C}^{-1}$ to $-0.007 \% \cdot{ }^{\circ} \mathrm{C}^{-1}$.

In the present work, a kind of simple-structure thermal compensation unit was used to compensate the thermal characteristics of the GMR current sensor. As the sensitivity and output of GMR materials are linearly related to its input power supply, a voltage power supply that increases with the 
rising temperature can compensate for the decreased sensitivity and output of GMR materials with the rising temperature.

Figure 13. Temperature response of GMR current sensor. GMROut + is the positive output of the GMR current sensor. GMROut- is the negative output of the GMR current sensor. GMROut is the differential output of the GMR current sensor. The amplitude response was $28.43 \mathrm{mV} \cdot \mathrm{A}^{-1}$ at $-15^{\circ} \mathrm{C}$, but decreased to $26.49 \mathrm{mV} \cdot \mathrm{A}^{-1}$ at $80{ }^{\circ} \mathrm{C}$. The differential output of the GMR current sensor decreased with the rising temperatures, and the TMCA is $0.0751 \% \cdot{ }^{\circ} \mathrm{C}^{-1}$. In contrast, the phase response was independent of temperature, and the phase lag with respect to the input current was $-5.18^{\circ}$.

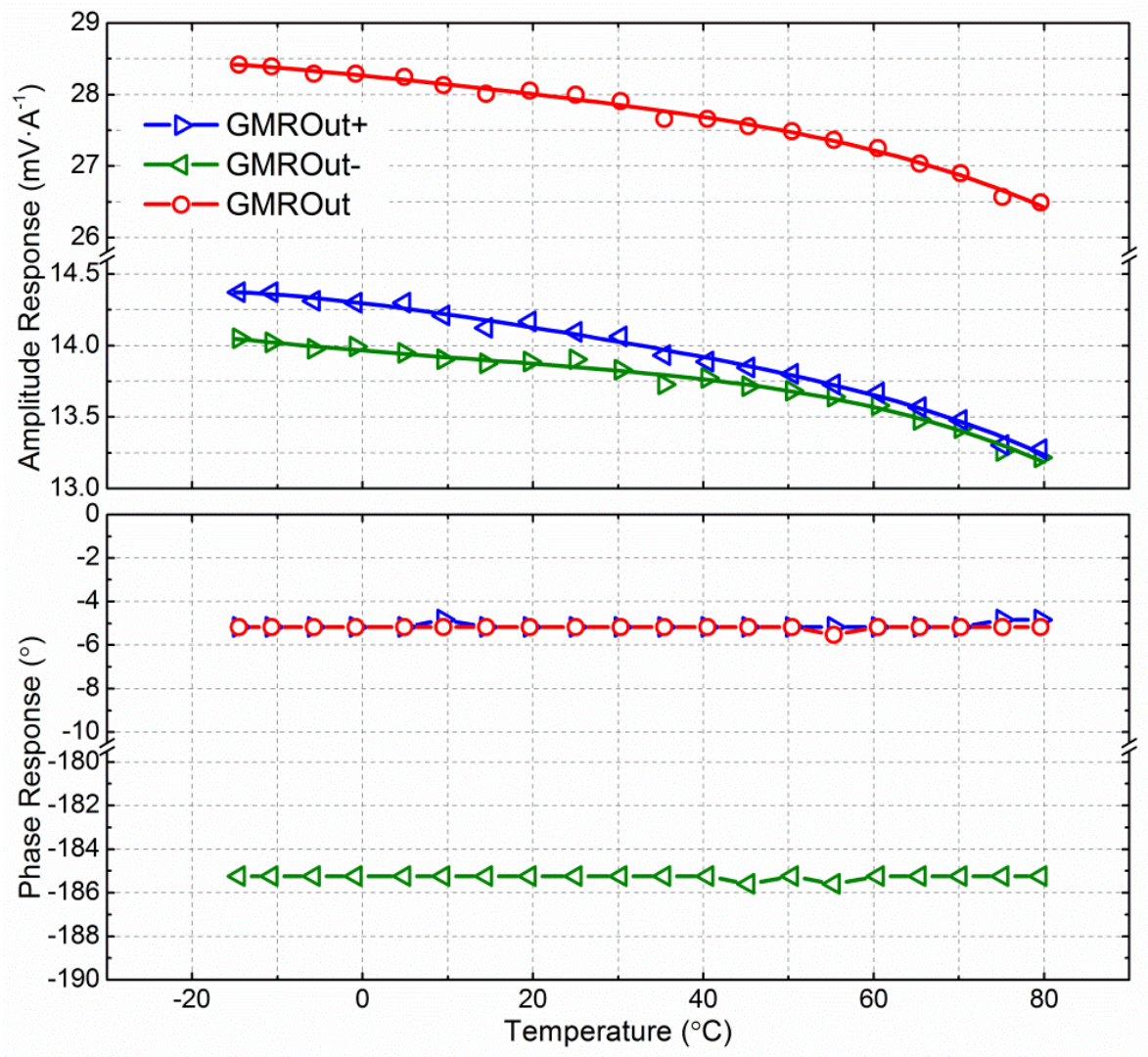

As shown in Figure 14(a), $V_{\text {in }}$ is the input voltage of the thermal compensation unit. $V T C_{\text {out }}$ and $V T C_{\text {out }}$ is the output of the thermal compensation unit, respectively, connected to the $V_{+}$and $V_{-}$of the GMR chip (as shown in Figure 4). $R_{n t c}$ is a linearized NTC thermistor, and $R_{h p}$ is a high precision resistor. The output of the thermal compensation unit that is connected to the power supply of the GMR chip can be described by Equation (7):

$$
V T C_{\text {out }+}=V_{\text {in }}\left(1+\frac{R_{h p}}{R_{n t c}}\right)
$$

The thermal characteristics of $R_{n t c}$ and $R_{h p}$ are shown in Figure 14(b). The resistance of $R_{n t c}$ is $5.1526 \mathrm{k} \Omega$ at the reference temperature of $20^{\circ} \mathrm{C}$, and the temperature coefficient of resistance (TCR) is $-2.6990 \times 10^{-4}{ }^{\circ} \mathrm{C}^{-1}$. The resistance of $R_{h p}$ is $0.9980 \mathrm{k} \Omega$ with almost no change in temperature. 
Figure 14. (a) Circuit diagram of the thermal compensation unit. (b) Thermal characteristics of the compensating resistors. $V_{\text {in }}$ is the input voltage of the thermal compensation unit. $\mathrm{VTC}_{\text {out }}$ and $\mathrm{VTC}_{\text {out- }}$ are output of the thermal compensation unit, respectively connected to the $\mathrm{V}+$ and $\mathrm{V}$ - of the GMR chip (as shown in Figure 4). $\mathrm{R}_{\text {ntc }}$ is a linearized NTC thermistor. Its resistance is $5.1526 \mathrm{k} \Omega$ at the reference temperature of $20^{\circ} \mathrm{C}$, and the temperature coefficient of resistance (TCR) is $-2.6990 \times 10^{-4}{ }^{\circ} \mathrm{C}^{-1}$. $\mathrm{R}_{\mathrm{hp}}$ is a high precision resistor, and the resistance is $0.9980 \mathrm{k} \Omega$ with almost no change in temperature.

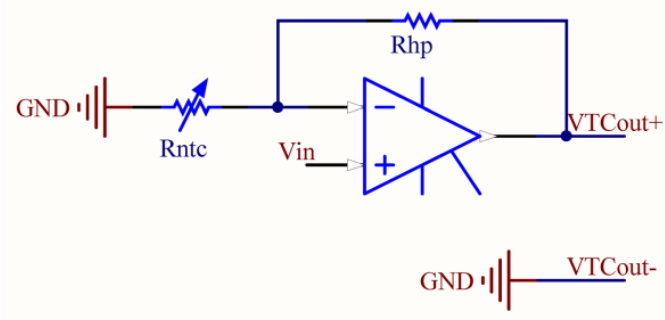

(a)

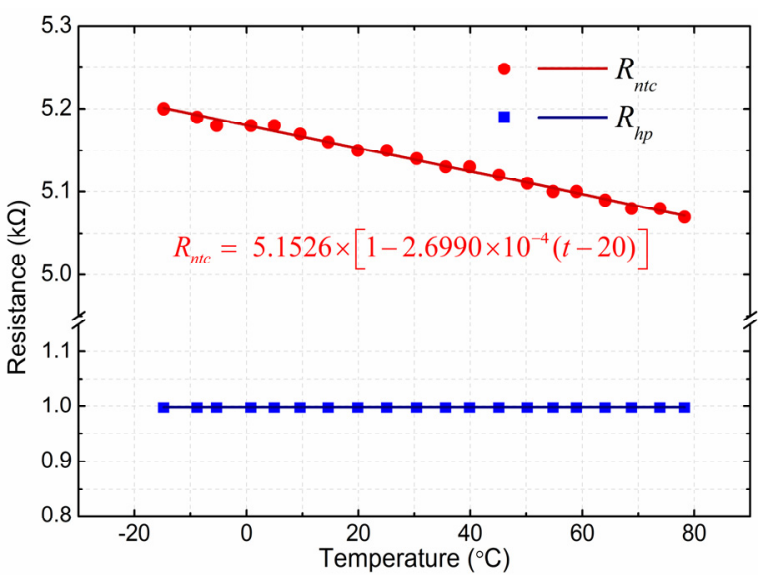

(b)

With a $50 \mathrm{~Hz}$ alternating input current, the thermal compensation of the GMR current sensor is shown in Figure 15. The power supply of the GMR chip is $5 \mathrm{~V}$ constant voltage supply before the thermal compensation, and the $V_{\text {in }}$ (as shown in Figure 14(a)) of the thermal compensation unit is $5 \mathrm{~V}$ when it is applied. The normalized amplitude response is 1.00 at the reference temperature of $20^{\circ} \mathrm{C}$.

Figure 15. Thermal compensation of the GMR current sensor. The power supply of the GMR chip is $5 \mathrm{~V}$ constant voltage supply before the thermal compensation, and the $\mathrm{V}_{\text {in }}$ (as shown in Figure 14(a)) of the thermal compensation unit is $5 \mathrm{~V}$ when it is applied. The normalized amplitude response is 1.00 at the reference temperature of $20{ }^{\circ} \mathrm{C}$. The maximum change of the amplitude response is $0.0751 \% \cdot{ }^{\circ} \mathrm{C}^{-1}$ before the thermal compensation, while the value reduces to $0.0335 \% \cdot{ }^{\circ} \mathrm{C}^{-1}$ after the thermal compensation.

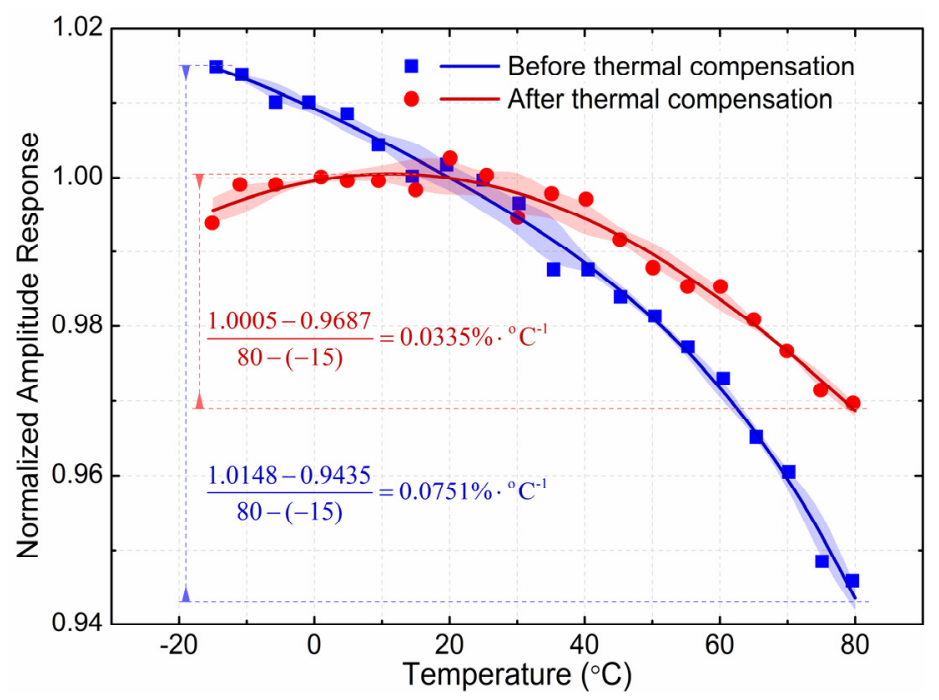


Before the thermal compensation, the amplitude response decreased monotonically with rising temperature. The maximum normalized value was 1.0148 at the temperature of $-15{ }^{\circ} \mathrm{C}$, while the minimum normalized value was 0.9435 at the temperature of $80{ }^{\circ} \mathrm{C}$, and the $T M C A$ is $0.0751 \% \cdot{ }^{\circ} \mathrm{C}^{-1}$ before the thermal compensation. After the thermal compensation, the amplitude response was parabolic with rising temperature. The maximum normalized value was 1.0005 at the temperature of $10{ }^{\circ} \mathrm{C}$, while the minimum normalized value was 0.9956 and 0.9435 respectively at the temperature of $-15{ }^{\circ} \mathrm{C}$ and $80{ }^{\circ} \mathrm{C}$, and the $T M C A$ decreased to $0.0335 \% \cdot{ }^{\circ} \mathrm{C}^{-1}$ after the thermal compensation. With this kind of simple-culture thermal compensation unit, the sensor obtained the appreciable reduction in temperature dependence.

Software compensation is another simple and effective method to achieve this purpose, in which, the current and the temperature are measured simultaneously. The output of the GMR current sensor can be calibrated and modified based on the measured temperature response curve using software compensation.

\section{Applications in Smart Grid}

A variety of currents need to be measured in the smart grid. The coverage of the magnitude and the frequency of typical currents in the smart grid are shown in Figure 16. The magnitude of currents varies from $1 \mu \mathrm{A}$ to $200 \mathrm{kA}$, and the frequency of currents varies from $\mathrm{DC}$ to $100 \mathrm{MHz}$, and the working state varies from steady-state to transient-state. Many of the currents in the figure are typical values found in the transmission lines and distributed networks. The diversity of these requirements is well matched by the versatility of GMR current sensors as described earlier.

Figure 16. Current measurement requirements of a smart grid.

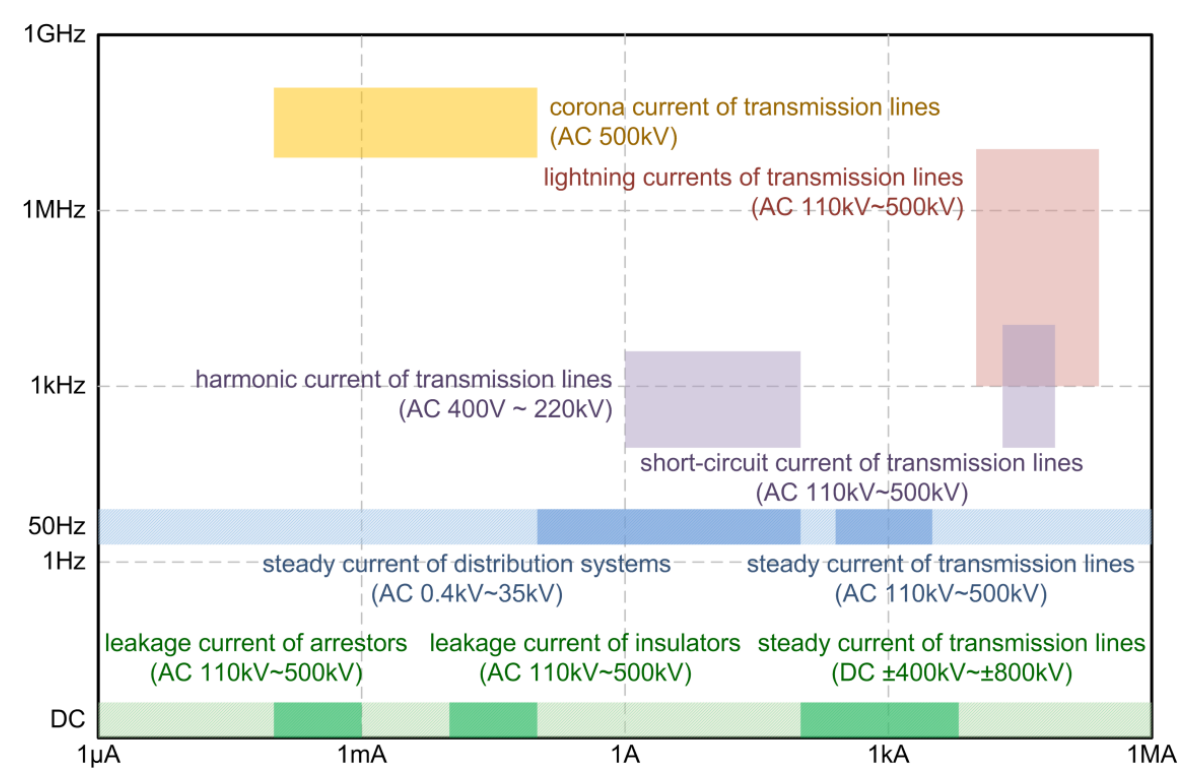

\subsection{Comparison of Current Sensors}

Current sensors play an extremely important role in power systems for the purpose of protection and control. Presently, current sensors applied in power systems mainly include current transformers (CTs), Rogowski coils, shunts, fiber-optic current transformers (FOCTs), fluxgate sensors, Hall effect sensors 
and GMR effect sensors, and they are mainly based on the following physical principles: Faraday's law of induction, Ohm's law of resistance, Faraday effect and magnetic field sensors [25,28,29]. The performance and characteristics of the current sensors mentioned above are compared in Table 2.

Table 2. Performance comparison of existing current sensors applied in power systems.

\begin{tabular}{|c|c|c|c|c|c|c|c|}
\hline Sensors & $C T$ & Rogowski & Shunt & $F O C T$ & Fluxgate & Hall & $G M R$ \\
\hline Volume & large & small & small & small & large & small & small \\
\hline Price & high & low & low & extra high & high & low & low \\
\hline $\begin{array}{l}\text { Frequency } \\
\text { Range }\end{array}$ & $0.05 \sim 10 \mathrm{kHz}$ & $0.1 \sim 100 \mathrm{MHz}$ & $\mathrm{kHz} \sim \mathrm{MHz}$ & $\sim 300 \mathrm{MHz}$ & $\sim 100 \mathrm{kHz}$ & $\sim 1 \mathrm{MHz}$ & $\sim 5 \mathrm{MHz}$ \\
\hline $\begin{array}{l}\mathrm{DC} \\
\text { Capability }\end{array}$ & No & No & Yes & Yes & Yes & Yes & Yes \\
\hline Sensitivity & $1 \mathrm{~V} \cdot \mathrm{A}^{-1}$ & $10 \mathrm{mV} \cdot \mathrm{A}^{-1}$ & $1 \mathrm{mV} \cdot \mathrm{A}^{-1}$ & high & high & $10 \mathrm{Oe}$ & $0.01 \mathrm{Oe}$ \\
\hline $\begin{array}{l}\text { Dynamic } \\
\text { Range }\end{array}$ & $1 \mathrm{~A} \sim 100 \mathrm{kA}$ & $0.1 \sim 100 \mathrm{kA}$ & $\mathrm{mA} \sim \mathrm{kA}$ & $1 \mathrm{~A} \sim 3 \mathrm{kA}$ & $1 \mathrm{~A} \sim 10 \mathrm{kA}$ & $10 \mathrm{~mA} \sim 35 \mathrm{kA}$ & $1 \mathrm{~mA} \sim 10 \mathrm{kA}$ \\
\hline Non-linearity & $0.05 \%$ & $0.05 \%$ & $0.01 \%$ & $0.2 \%$ & $\begin{array}{l}0.001 \% \sim \\
0.5 \%\end{array}$ & $0.1 \sim 1 \%$ & $0.01 \sim 0.05 \%$ \\
\hline $\begin{array}{l}\text { Temperature } \\
\text { Coefficient }\end{array}$ & -- & -- & -- & ${ }_{1}^{-0.4 \% \cdot{ }^{\circ} \mathrm{C}^{-}}$ & -- & $-0.3 \% \cdot{ }^{\circ} \mathrm{C}^{-1}$ & $\begin{array}{l}-0.1 \sim \\
-0.4 \% \cdot{ }^{\circ} \mathrm{C}^{-1}\end{array}$ \\
\hline Isolation & complex & complex & complex & simple & complex & complex & complex \\
\hline $\begin{array}{l}\text { Breakdown } \\
\text { Voltage }\end{array}$ & high & high & low & high & high & low & high \\
\hline
\end{tabular}

The current transformer, with its advantages of high stability and high breakdown voltage, is the most widely applied for alternating current sensing in traditional power systems. Because it is based on Faraday's law of induction, it can't be applied in direct current measurement, and with its disadvantages of large size, high price, limited bandwidth and large consumption of metal resources, it is only used in power stations and substations. The Rogowski coil, with favorable features of high bandwidth and capability of measuring large currents, is mainly used for transient large current sensing, and can be easily installed on the transmission lines as a small size and low price unit. However, Rogowski coils have poor accuracy when sensing small and low frequency currents, which limits their broader application.

Shunts are mainly applied in power electronics and direct current converter stations. They are the most cost effective solution, but their disadvantages are obvious: the measured current has to be interrupted into the sensor, an overcurrent may permanently damage it, and the intrinsic inductance limits the accuracy and bandwidth. Fiber-optic current transformers have developed rapidly in recent years. Their advantages of effective isolation from high potentials, immunity against electromagnetic interferences, and wide bandwidth offer a wide potential application in power systems. However, the extremely complicated structure, high price, susceptibility to the temperature and polarization under direct current are problems that need to be solved. 
Hall effect current sensors are mainly applied in non-contact current measurements. And indeed, currently, most non-contact current measurement probes are based on the Hall effect. However, the problems of the Hall effect sensor are low sensitivity, low breakdown voltage, and susceptibility to the temperature, which limit it to applications in high voltage power systems. The fluxgate technology can significantly improve the accuracy of magnetic field sensors such as Hall effect sensor, but because of its high cost and size requirements, fluxgate technology is usually only employed in calibration systems, diagnosis systems and laboratory equipment.

Compared with the current sensors mentioned above, the GMR effect sensor has advantages of high sensitivity, high linearity, small volume, low cost, simple structure and lower susceptibility to the temperature, which make it the most promising for current measurement in smart grids, especially in distributed transmission lines.

\subsection{Distributed Monitoring}

One major challenge in a smart grid is how to realize real-time monitoring of each node in the distributed electrical power system. Currently, real-time sensor systems such as traditional current transformers and fiber-optic current transformers, are only applied in some key places like power stations and substations, and there are currently no suitable real-time sensor systems capable of monitoring each distributed transmission line in the smart grid. With the advantages of small volume, low cost and simple-structure, the GMR current sensor can be readily implemented to monitor large-scale distributed power systems, and to provide accurate real-time information for each grid.

\subsection{Steady-State Monitoring}

In an electrical power system, the steady-state current of various electrical equipment must be monitored, such as transmission lines, power substations, AC transformer stations, DC converter stations, distribution networks, and user networks. The current can be either direct current or alternating current. In the case of DC converter stations, measurement of both direct and alternating current is necessary. The optical current transformer and fluxgate current transformer are the two most commonly-used current transformers in such DC converter stations. However, these two types of current transformers are expensive, complex, and possess adverse environmental effects. In contrast, the GMR current sensor we describe here has excellent DC and AC performance, is cost-effective, and can be readily applied to steady-state monitoring.

\subsection{Transient-State Monitoring}

In a smart grid, transient-state currents, such as lightning currents, switch impulse currents, harmonic currents and leakage currents, also needs to be monitored. However, these currents have large amplitudes and frequency ranges, making accurate measurements difficult. For instance, lightning current can reach as high as $200 \mathrm{kA}$, with frequencies as high as $100 \mathrm{MHz}$, and leakage current can be as small as $1 \mathrm{~mA}$. The saturation field of multilayered GMR materials reaches 2,000 Oe $(1 \mathrm{Oe}=0.1 \mathrm{mT})$, and a sensitivity of $0.1 \% \cdot \mathrm{Oe}^{-1}$. In addition, the saturation field of spin valve GMR 
materials reaches 50 Oe and a sensitivity of $1.0 \% \cdot \mathrm{Oe}^{-1}$. Therefore, we can utilize GMR current sensors based on these two kinds of materials to measure wide ranges of currents.

\subsection{Power Monitoring}

The sensitivity and output of GMR materials are linearly related to their input power supply. If we connect the power supply pins of the GMR current sensors to measure an electrical system, the output of the GMR current sensor is related to the voltage and current of the measured electrical system. Therefore, we can calculate the system's instantaneous power. A possible device used to measure alternating instantaneous power [21], and a circuit used to measure the discharge power of a battery using a GMR sensor have been developed [30]. A kind of wattmeter based on an anisotropic magnetoresistive (AMR) sensor was designed and tested experimentally [31], and a practical magnetoresistive wattmeter was designed to measure active power at industrial frequencies, which reached the $700 \mathrm{~W}$ power level with an uncertainty of less than $1 \%$ [32].

Taking into account the power delivered to a cosine circuit, the voltage and current of the load can be described as:

$$
\begin{aligned}
u(t) & =\sqrt{2} V_{r m s} \cos (\omega t+\theta) \\
i(t) & =\sqrt{2} I_{r m s} \cos (\omega t)
\end{aligned}
$$

where $V_{r m s}$ is the root mean square of the voltage, $I_{r m s}$ is the root mean square of the current, $\omega$ is the angular frequency of the circuit, and $\theta$ is the initial phase of the voltage.

The instantaneous power of the load can be described as:

$$
\begin{aligned}
p(t) & =u(t) i(t) \\
& =\sqrt{2} V_{r m s} \cos (\omega t+\theta) \cdot \sqrt{2} I_{r m s} \cos (\omega t) \\
& =V_{r m s} I_{r m s} \cos \theta+V_{r m s} I_{r m s} \cos (2 \omega t+\theta)
\end{aligned}
$$

The relationship between output and input of the GMR sensor can be described as:

$$
\begin{aligned}
u_{\text {out }} & =u(t)(A i(t)+B) \\
& =\sqrt{2} V_{r m s} \cos (\omega t+\theta)\left(A \sqrt{2} I_{r m s} \cos (\omega t)+B\right) \\
& =2 A V_{r m s} I_{r m s} \cos (\omega t+\theta) \cos (\omega t)+\sqrt{2} B V_{r m s} \cos (\omega t+\theta) \\
& =A V_{r m s} I_{r m s} \cos \theta+A V_{r m s} I_{r m s} \cos (2 \omega t+\theta)+\sqrt{2} B V_{r m s} \cos (\omega t+\theta)
\end{aligned}
$$

where $A$ and $B$ are the sensitivity and offset output of the GMR sensor. $A V_{r m s} I_{r m s} \cos \theta$ is related to the active power of the load, $A V_{r m s} I_{r m s} \cos (2 \omega t+\theta)$ is related to the reactive power of the load, and $A V_{r m s} I_{r m s} \cos \theta+A V_{r m s} I_{r m s} \cos (2 \omega t+\theta)$ is related to the instantaneous power of the load.

To obtain the active power, Ramírez Muñoz et al. designed a low-pass filter to remove the AC frequency components [32]. In the works of this paper, with the aid of a digital signal processing technique, both the active power (DC component) and the reactive power (2-harmonic components) are extracted from the output signal, and then the instantaneous power of the load is calculated and the effect of the GMR sensor offset is eliminated. 
To demonstrate the capability of GMR current sensor mentioned above to measure instantaneous power, the GMR current sensor was used to measure alternating instantaneous power delivered to a $10 \Omega$ resistor. The resistor was powered by an AC voltage source at $50 \mathrm{~Hz}$ and $10 \mathrm{~V}$ peak to peak. As shown in Figure 17, the output of the GMR current sensor contained two frequency components: $50 \mathrm{~Hz}$ and $100 \mathrm{~Hz}$. The $100 \mathrm{~Hz}$ frequency component showed the alternating instantaneous power of the resistor, and the $50 \mathrm{~Hz}$ frequency component was caused by the asymmetry of the Wheatstone bridge.

Figure 17. Power monitoring of GMR sensor. The $10 \Omega$ resistor is powered by a $50 \mathrm{~Hz}$ and $10 \mathrm{~V}$ peak to peak AC voltage source. The two power supply terminals of the GMR chip are connected to the two terminals of the $10 \Omega$ resistor load. Current is the AC current passing through the $10 \Omega$ resistor load. GMROut is the differential output of the GMR current sensor. GMROut-50Hz is the $50 \mathrm{~Hz}$ frequency component of the GMROut, which is caused by the asymmetry of the Wheatstone bridge, and the frequency is the same as the voltage of the $10 \Omega$ resistor load. GMROut- $100 \mathrm{~Hz}$ is the $100 \mathrm{~Hz}$ frequency component of the GMROut, which showed the instantaneous power of the $10 \Omega$ resistor load.

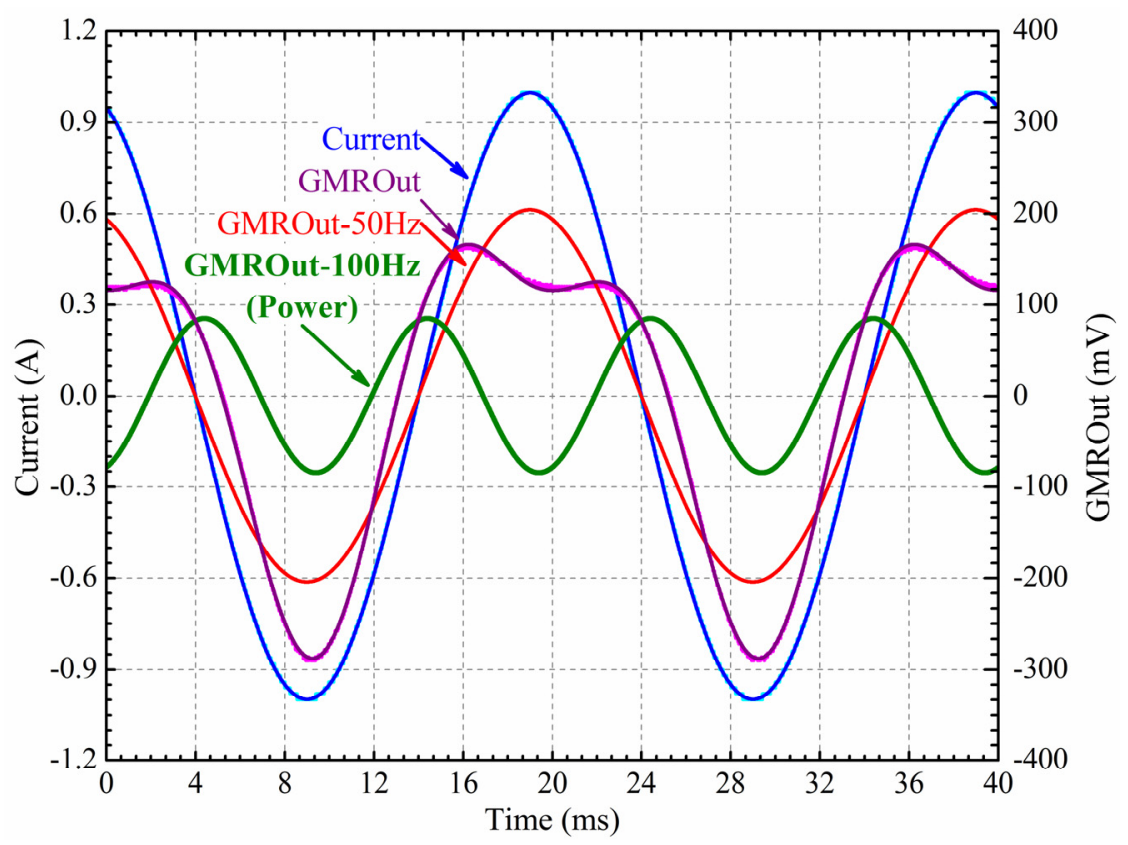

As mentioned, due to material processing and manufacturing technology limitations, it is impossible to manufacture the four resistive elements shown in Figure 4 identically. This results in voltage variations between the positive and negative outputs of the GMR current sensor when no current passes through the wire being measured. Therefore, there is a component in the output of the GMR current sensor, which the magnitude of the component is linearly related to the voltage of the load, and frequency is the same as the voltage of the load. This offset needs to be taken into account and mitigated in practice.

\section{Conclusions}

The design and development of a GMR current sensor for smart grid applications were discussed. Characterization of the sensor was done to study its static, dynamic and thermal characteristics. The 
static characteristics of the sensor consist of the following performance parameters: operation range, sensitivity, linearity, and accuracy. The sensitivity of the sensor is $28 \mathrm{mV} \cdot \mathrm{A}^{-1}$. At an input range of $0 \sim \pm 5 \mathrm{~A}$, the linearity reached $99.972 \%$, and the maximum deviation was $2.717 \%$. At an input range of $0 \sim \pm 2$ A, the linearity reached $99.993 \%$, and the maximum deviation was $1.757 \%$. Furthermore, dynamic characterization of the sensor showed that the frequency response of the GMR current sensor was $-0.45 \mathrm{~dB}$ at $1 \mathrm{kHz}$ input current and $-1.5 \mathrm{~dB}$ at $10 \mathrm{kHz}$ input current. Lastly, the thermal characterization showed that the maximum change of amplitude response in temperature (TMCA) of the GMR sensor was $0.0751 \% \cdot{ }^{\circ} \mathrm{C}^{-1}$, and the value decreased to $0.0335 \% \cdot{ }^{\circ} \mathrm{C}^{-1}$ with a simple-structure thermal compensation unit.

The GMR current sensor described in this paper can be readily applied to monitor a smart grid in real-time. In the case of distributed monitoring, steady-state monitoring, and transient-state monitoring, the GMR current sensor provides excellent performance, and is cost-effective. Moreover, with appropriate design modifications, it can also be used for power monitoring, which potentially has a vast market in residential power systems. With its high sensitivity, high linearity, small volume, low cost and simple structure, the proposed GMR current sensor has bright prospects in the measurement and monitoring of smart grids.

\section{Acknowledgments}

This work was supported in part by the National Natural Science Foundation of China under Grant 51028701 and Grant 51077085.

\section{References}

1. Potter, C.W.; Archambault, A.; Westrick, K. Building a smarter smart grid through better renewable energy information. In Proceedings of Power Systems Conference and Exposition, Seattle, WA, USA, 15-18 March 2009; pp. 1-5.

2. Gungor, V.C.; Sahin, D.; Kocak, T.; Ergut, S.; Buccella, C.; Cecati, C.; Hancke, G.P. Smart Grid Technologies: Communication Technologies and Standards. IEEE Trans. Ind. Informa. 2011, 7, 529-539.

3. Hashmi, M.; Hanninen, S.; Maki, K. Survey of smart grid concepts, architectures, and technological demonstrations worldwide. Innovative Smart Grid Technologies (ISGT Latin America). In Proceedings of 2011 IEEE PES Conference on 2011, Medellin, Colombia, 19-21 October 2011; pp. 1-7.

4. Baibich, M.N.; Broto, J.M.; Fert, A.; Van Dau, F.N.; Petroff, F.; Eitenne, P.; Creuzet, G.; Friederich, A.; Chazelas, G. Giant Magnetoresistance of $(001) \mathrm{Fe} /(001) \mathrm{Cr}$ Magnetic Superlattices. Phys. Rev. Lett. 1988, 61, 2472-2475.

5. Binasch, G.; Grünberg, P.; Saurenbach, F.; Zinn, W. Enhanced magnetoresistance in layered magnetic-structures with antiferromagnetic interlayer exchange. Phys. Rev. B 1989, 39, 4828-4830.

6. Fert, A.; Grünberg, P.; Barthélémy, A.; Petroff, F.; Zinn, W. Layered magnetic structures: In terlayer exchange coupling and giant magnetoresistance. J. Magn. Mater. 1995, 140, 1-8. 
7. Thompson, S.M. The discovery, development and future of GMR: The Nobel Prize 2007. J. Phys. D-Appl. Phys. 2008, 41, 1-20.

8. Childress, J.R.; Fontana, R.E. Jr., Magnetic recording read head sensor technology. Compt. Rendus Phys. 2005, 6, 997-1012.

9. Pelegrí, J.; Ramírez, D.; Sanchis, E.; Navarro, A.E.; Casans, S. Giant magnetoresistive sensor in conductance control of switching regulators. IEEE Trans. Magn. 2000, 36, 3578-3580.

10. Olson, E.R.; Lorenz, R.D. Integrating Giant Magnetoresistive Current and Thermal Sensors in Power Electronic Modules. In Proceedings of Applied Power Electronics Conference and Exposition, Miami Beach, FL, USA, 9-13 February 2003; Volume 2, pp. 773-777.

11. Laimer, G.; Kolar, J.W. Design and Experimental Analysis of a DC to $1 \mathrm{MHz}$ Closed Loop Magnetoresistive Current Sensor. In Proceedings of Applied Power Electronics Conference and Exposition, Austin, TX, USA, 6-10 March 2005; pp. 1288-1292

12. Singh, R.P.; Khambadkone, A.M. Giant Magneto Resistive (GMR) effect based current sensing technique for low voltage/high current voltage regulator modules. IEEE Trans. Power Elect. 2008, 23, 915-925.

13. Schneider, P.E.; Horio, M.; Lorenz, R.D. Integrating Giant Magneto-Resistive (GMR) Field Detectors for High Bandwidth Current Sensing in Power Electronic Modules. In Proceedings of Energy Conversion Congress and Exposition (ECCE), Atlanta, GA, USA, 12-16 September 2010, pp. 1260-1267.

14. Ricken, W.; Liu, J.; Becker, W.J. GMR and eddy current sensor in use of stress measurement. Sens. Actuators A Phys. 2001, 91, 42-45.

15. Yamada, S.; Chomsuwan, K.; Fukuda, Y.; Iwahara, M.; Wakiwaka, H.; Shoji, S. Eddy-current testing probe with spin-valve type GMR sensor for printed circuit board inspection. IEEE Trans. Magn. 2004, 40, 2676-2678.

16. Thessler, S.; Kooistra, L.; Teye, F.; Huitu, H.; Bregt, A.K. Geosensors to support crop production: Current applications and user requirements. Sensors 2011, 11, 6656-6684.

17. Xu, L.; Yu, H.; Han, S.J.; Osterfeld, S.; White, R.L.; Pourmand, N.; Wang, S.X. Giant Magnetoresistive Sensors for DNA Microarray. IEEE Trans. Magn. 2008, 44, 3989-3991.

18. Wang, S.X.; Li, G. Advances in giant magnetoresistance biosensors with magnetic nanoparticle tags: Review and outlook. IEEE Trans. Magn. 2008, 44, 1687-1702.

19. Hall, D.A.; Gaster, R.S.; Lin, T.; Osterfeld, S.J.; Han, S.; Murmann, B.; Wang, S.X. GMR biosensor arrays: A system perspective. Biosens. Bioelectron. 2010, 25, 2051-2057.

20. Hall, D.A.; Gaster, R.S.; Osterfeld, S.J.; Murmann, B.; Wang, S.X. GMR biosensor arrays: Correction techniques for reproducibility and enhanced sensitivity. Biosens. Bioelectron. 2010, 25, 2177-2181.

21. Reig, C.; Cubells-Beltran, M.D.; Munoz, D.R. Magnetic field sensors based on Giant Magnetoresistance (GMR) technology: Applications in electrical current sensing. Sensors 2009, 9 , 7919-7942.

22. Qian, Z.H.; Wang, D.X.; Daughton, J.M.; Tondra, M.; Nordman, C.; Popple, A. Linear spin-valve bridge sensing devices. IEEE Trans. Magn. 2004, 40, 2643-2645.

23. Pelegrí, J.; Ramírez, D.; Freitas, P.P.; Ku, W.; Li, H.; Casans, S. A novel spin-valve bridge sensor for current sensing. IEEE Trans. Instrum. Meas. 2001, 1, 422-424. 
24. Pelegrí, J.; Ejea, J.B.; Ramírez, D.; Freitas, P.P. Spin-valve current sensor for industrial applications. Sens. Actuators A Phys. 2003, 105, 132-136.

25. Xiao, C.C; Zhao, L.Y.; Asada, T.; Odendaal, W.G.; van Wyk, J.D. An Overview of Integratable Current Sensor Technologies. In Proceedings of 38th Industry Applications Conference, Conference Record of the 2003, Salt Lake City, UT, USA, 12-16 October 2003; pp. 1251-1258.

26. Moreno, J.S.; Muñoz, D.R.; Cardoso, S.; Berga, S.C.; Antón, A.; de Freitas, P. A non-invasive thermal drift compensation technique applied to a spin-valve magnetoresistive current sensor. Sensors 2011, 11, 2447-2458.

27. Muñoz, D.R.; Moreno, J.S.; Berga, S.C.; Montero, E.C.; Escrivà, C.R.; Antón, A. Temperature compensation of Wheatstone bridge magnetoresistive sensors based on generalized impedance converter with input reference current. Rev. Sci. Instrum. 2006, 77, 1-6.

28. Ziegler, S.; Woodward, R.C.; Ho-Ching Iu, H.; Borle, L.J. Current sensing techniques: A review. IEEE Sens. J. 2009, 9, 354-376.

29. Pavel R. Electric Current Sensors: A Review. Meas. Sci. Technol. 2010, 11, 1-23.

30. Ramírez, D.; Pelegrí, J. GMR sensors manage batteries. EDN 1999, 44, 138.

31. Vopálenský, M.; Platil A.; Kašpar, P. Wattmeter with AMR sensor. Sens. Actuators A Phys. 2005, 123-124, 303-307.

32. Muñoz, D.R.; Moreno, J.S.; Berga, S.C.; Antón, A. Active power analog front-end based on a Wheatstone-type magnetoresistive sensor. Sens. Actuators A Phys. 2011, 169, 83-88.

(C) 2012 by the authors; licensee MDPI, Basel, Switzerland. This article is an open access article distributed under the terms and conditions of the Creative Commons Attribution license (http://creativecommons.org/licenses/by/3.0/). 